Steven Megson Plymouth University, Plymouth, UK

ÖZGÜN EMRE CAN Wildlife Conservation Research Unit, Department of Zoology, University of Oxford, Oxford, UK

\section{Conservation and reintroduction of a critically endangered plant Euryodendron excelsum}

The Critically Endangered, monotypic Euryodendron excelsum H.T. Chang (Family Theaceae), is endemic to southern China, to the Bajia region of Guangdong Province. This rare species is ranked as the second most threatened species in China and is subject to national protection. Supported by the National Science Foundation of China, the Plant Science Institute of Yunnan University has been carrying out conservation research and reintroduction actions for E. excelsum. We have found that the species is now present in only one remnant, highly fragmented population, with 179 individuals. The species has no clonal growth and propagates only by seeds. The major threats to the species' survival are its small population size and the high frequency of destruction by people. As seedling survival appears to be poor, the conservation of E. excelsum needs to include the protection of its habitat and of the remnant individuals, and artificial propagation and ex situ seedling establishment for a future reintroduction programme.

In February 2009 seeds were collected and germinated in a greenhouse at Yunnan University. About 2,00o seedlings had successfully propagated by October, when c. 300 seedlings of c. $12 \mathrm{~cm}$ height were then transplanted to the species' original range. At the same time seedlings were planted in Hekou county and Xishuangbana Botanical Garden. By July 2012, nearly 3 years later, the transplanted seedlings had grown to a height of c. $150 \mathrm{~cm}$, with c. 40,80 and $70 \%$ survival in Bajia, Hekou county and Xishuangbana Botanical Garden, respectively.

These conservation studies and actions will help with the design of conservation and reintroduction strategies for $E$. excelsum. The Plant Science Institute of Yunnan University is now carrying out further studies on the conservation and reintroduction of this species. The ultimate aim is to restore E. excelsum to the wild.

ShiKang Shen, Yuehua Wang, Aili Zhang, Fugin $W_{U}$ and LIANII JIANG Plant Science Institute, School of Life Sciences, Yunnan University, Kunming, China

E-mailwangyh58212@yahoo.com.cn

LINA JIANG School of Horticulture and Landscape, Yunnan Agriculture University, Kunming, China

\section{The 11th meeting of the Conference of the Parties to the Convention on Biological Diversity- progress on the road to achieving the Aichi Biodiversity Targets}

The 11th meeting of the Conference of the Parties (COP 11) to the Convention on Biological Diversity (CBD), which took place in October 2012 in Hyderabad, India, resulted in a range of outcomes to help advance the conservation of biological diversity, the sustainable use of its components and the fair and equitable sharing of the benefits arising out of the utilization of genetic resources. This meeting comes 2 years after arguably the most important meeting of the CBD - COP 10 in Nagoya, Japan-which adopted the Nagoya Protocol on Access to Genetic Resources and the Fair and Equitable Sharing of Benefits Arising from their Utilization, and the Strategic Plan for Biodiversity 2011-2020 with its ambitious 20 Aichi Biodiversity Targets (see Oryx, 45, 1-2).

COP 11 served to review progress and identify actions required to support the parties, in particular developing country parties, in implementing the Strategic Plan. Implementation was reiterated during the meeting as the top priority of the new CBD Executive Secretary, Braulio Ferreira de Souza Dias. The COP adopted a total of 33 decisions (http://www.cbd.int/cop11) on a wide range of topics, including those the Convention has covered since it came into force in 1993 (http://www.cbd.int/programmes).

Support for National Biodiversity Strategies and Action Plans (NBSAP) was identified as a priority issue. A new partnership between the CBD and the UN Development and Environment Programmes called the NBSAP Forum was launched in Hyderabad, to assist countries with their NBSAPs and provide guidance on mainstreaming biodiversity into national development agendas (http://www. nbsapforum.net).

The mobilization of resources required for implementing the Convention was the most contentious issue on the COP agenda. The report of the High-Level Panel on Global Assessment of Resources for Implementing the Strategic Plan for Biodiversity 2011-2020, commissioned by the governments of UK and India (http://www.cbd.int/doc/ meetings/cop/cop-11/official/cop-11-14-add2-en.pdf), was presented to the COP. This estimated the costs for implementing the 20 Aichi Targets at USD 150-440 billion per year (see also Science, http://dx.doi.org/10.1126/science. 1229803).

Disagreement over baselines and the role of domestic funding versus direct flow of resources from the North to the South hampered discussions on targets for the Resource Mobilization Strategy of the Convention. After intense negotiations a decision was made very late in the final plenary that includes the target of doubling total biodiversity-related international financial resource flows to 
developing countries by 2015 and at least maintaining that level until 2020.

Other key decisions covered: (1) Agreement to a preliminary list of indicators for measuring progress towards achievement of the Aichi Targets. Further work will be undertaken on developing and applying the indicators. The Biodiversity Indicators Partnership (http:// www.bipindicators.net) will provide assistance to parties with the application of indicators at the national level. (2) The Nagoya Protocol, which has been ratified or acceded by only eight countries whereas 50 are required for it to enter into force. The Intergovernmental Committee for the Nagoya Protocol will reconvene for a third meeting to progress the development of the working arrangements for the new Protocol (http://www.cbd.int/abs). (3) Continuation of the process of assembling information on Ecologically or Biologically Significant Marine Areas, collected through regional workshops. (4) Continued engagement with the United Nations Framework Convention on Climate Change, in particular on biodiversity safeguards for Reducing Emissions from Deforestation and Forest Degradation in Developing Countries. (5) Continued progress to develop guidance on linkages between biodiversity and poverty, through an expert group based on the Dehradun Recommendations on biodiversity for poverty eradication and development.

The meeting was attended by c. 6,00o representatives of governments, UN agencies, international organizations, indigenous and local communities, research and business. Hundreds of side meetings demonstrated the breadth of projects and initiatives happening on the ground for conservation and the sustainable use of biodiversity. Whether the meeting outcomes translate into improvements for ecosystems, species and genetic biodiversity, or human well-being, will become more apparent over the next few years as the Convention continues to evaluate progress in achieving the Aichi Biodiversity Targets. The next COP will be in the Republic of Korea in 2014.

Peter Herkenrath and Melissa JaQues UNEP World Conservation Monitoring Centre, Cambridge, UK

E-mail peter.herkenrath@unep-wcmc.org

\section{Third Guangxi International Orchid Symposia}

In May 2012 the 3rd Guangxi Orchid Symposium took place in Nanning, the capital of Guangxi, China, and in the Yachang National Orchid Nature Preserve in Leye County. There were 12 international and more than 80 Chinese participants, including the Vice Governor of Guangxi, Dr Chen Zhangliang, who is in charge of, among other things, biodiversity conservation in the province. Dr Mike Maunder of Florida International University spoke at the opening ceremony and gave a keynote presentation on IUCN's new reintroduction guidelines. In another keynote presentation Dr Richard Primack of Boston University gave an overview of global plant conservation. Dr Keping Ma, Professor at the Institute of Botany, Chinese Academy of Sciences, introduced the newly launched Chinese biodiversity informatics platform. Other researchers presented studies on populations, pollination and conservation of Chinese wild orchids.

As well as providing a platform for the exchange of the latest research findings in orchid biology and conservation, the Guangxi Orchid Symposia bring decision-makers, natural-area managers, scientists and other stakeholders together. The symposium series has yielded several significant benefits. The 1st Symposium stimulated the promotion of the Yachang nature preserve to a national preserve of the State Forestry Administration of China, a category that includes national funding for protection. The 1st and the 2nd symposia also stimulated the establishment of the Yachang Orchid Research Center. The 3rd symposium promoted the idea of establishing a biodiversity centre in Guangxi and an international orchid research institute. Because Guangxi is one of the three provinces in China with the greatest biodiversity, these initiatives will have conservation significance at the provincial, national, and international levels.

HoNG LIU Department of Earth and Environment, Florida International University, Miami, Florida, USA, and Fairchild Tropical Botanic Garden, Coral Gables, Florida, USA

E-mail hliu@fiu.edu 